\title{
COVID-19 e industria aeronáutica. 10 situaciones probables de crisis $\left.{ }^{*}\right)$
}

\author{
COVID-19 and aeronautics industry. 10 Probable Critical Scenarios
}

\author{
Griselda Delia Capaldo $\left.{ }^{* *}\right)$ \\ Universidad de Buenos Aires (Buenos Aires, Argentina)
}

\begin{abstract}
Resumen: La Real Academia Española define a la crisis, en su primera acepción, como un cambio profundo y de consecuencias importantes en un proceso o una situación, o en la manera en que estos son apreciados. La pandemia generada por la propagación del virus SARS-CoV-2, que causa COVID-19, ha impactado sobre múltiples escenarios en múltiples escalas. La industria aeronáutica, que por definición engloba no solo al transporte aéreo sino también a todas las infraestructuras, servicios y procesos asociados al mismo, incluido el de construcción y mantenimiento de aeronaves, ha sido una de las actividades afectadas. El presente trabajo apunta a describir al menos diez de esas situaciones de crisis, en sus distintas escalas (global, regional y local). El lapso temporal abarcado por este artículo se extiende hasta julio de 2020. Por su naturaleza, se trata de una investigación exploratoria y descriptiva. Atendiendo a esas escalas, este artículo focaliza su atención en el análisis de las medidas tomadas por la Organización de Aviación Civil Internacional $(\mathrm{OACl}$ ) y por la International Air Transport Association (IATA) a nivel global, por la Unión Europea (UE) y por la Comisión Latinoamericana de Aviación Civil (CLAAC) a nivel regional y, a nivel local, por un grupo seleccionado de Estados.
\end{abstract}

Palabras clave: Transporte aéreo - COVID-19 - Industria aerocomercial - IATA - OACI - Crisis del sector aéreo

\begin{abstract}
The Spanish Royal Academy of Language defines "crisis", in its first sense, as a profound change with important consequences in a process or situation, or in the way in which they are assessed. The pandemic engendered by the spread of the SARS-CoV-2 virus, which causes COVID-19, has impacted on multiple scenarios at multiple scales. The aeronautical industry, which by definition encompasses not only air transport but also all the facilities, services and processes associated with it, including the construction and maintenance of aircraft, has been one of the activities affected by the global pandemic. The present work aims to describe at least ten of those critical situations, at their different scales (global, regional and local). The length of time covered by the present work extends to July 2020. Paying attention on its nature, this is an exploratory and descriptive research. Taking these scales into account, this article focuses on the analysis of the measures taken by the International Civil Aviation Organization (ICAO) and by the International Air Transport Association (IATA) at a global level, by the European Union (EU) and by the Latin American Civil Aviation Commission (CLAAC) at the regional level and, at the local level, by a selected group of States.
\end{abstract}

Keywords: Air transport - Covid-19 - Commercial air activities - IATA - OACI - Crisis in aviation

$\left({ }^{*}\right) \quad$ Nota del Editor: este artículo fue recibido el 4 de junio de 2020 y su publicación fue aprobada el 19 de setiembre de 2020.

$\left(^{* *}\right)$ Doctora en Derecho por la Universidad de Buenos Aires, Argentina, donde desempeña la cátedra de "Derecho de la Navegación y Derecho Aéreo". Es investigadora principal del Consejo Nacional de Investigaciones Científicas y Tecnológicas - CONICET, Argentina. Es miembro Post-doctoral de la Alexander von Humboldt Stiftung, Universität zu Köel, Germany (2001-2002) ORCID: https://orcid. org/0000-0003-3702-4594. Correo electrónico: gcapaldo@derecho.uba.ar 


\section{Introducción}

El vocablo 'crisis' proviene del griego kpíon (krísis), es decir, 'decisión', y éste del verbo kpíveıv (krínein), esto es, decidir, separar, juzgar. La crisis, como posible 'separación' o 'rotura', es un punto crucial y decisivo. Etimológicamente, 'crisis' es el juicio formado sobre una cosa después de examinarla cuidadosamente. De ahí proviene el término 'crítica', que supone el estudio de algo para luego emitir un juicio. Toda crisis nos obliga a pensar. El vocablo también designa el momento en que se produce un cambio muy marcado en algo, o en una situación, o en un proceso. Desde este sentido etimológico y lingüístico será abordado el presente trabajo, y no en el sentido de "situación mala o difícil", como lo define la Real Academia en su tercera acepción.

Peter Frankopan, historiador inglés especializado en historia de las pandemias, sostiene que el efecto más notable de las conquistas mongoles sobre la transformación de Europa no fue resultado del comercio, la guerra, la cultura o la moneda, sino de la epidemia de peste negra (Frankopan, 2016, p.178) ${ }^{(1)}$.

Los itinerarios comerciales que unían a Europa con el resto del mundo conocido hacia el año 1346, también se convirtieron en rutas para la transmisión de la peste negra. $Y$ ahora, la propagación del virus SARS-CoV-2, que causa COVID-19, llegó al mundo occidental a través de los itinerarios comerciales de la aviación (Christidis et Christodoulou, 2020, pp. 1-2).

Por nuestra parte, creemos que el coronavirus ha colocado a la humanidad en una aporía, pues desafía las mentes de científicos, políticos, estrategas e infectólogos. Aún no sabemos cómo saldremos de ella ni cuál será el mapa de las nuevas relaciones internacionales de poder que se irá dibujando con el correr de los meses.

La industria aeronáutica, que por definición engloba no solo al transporte aéreo sino también a todos los servicios asociados a él (como los de tránsito aéreo, rampa, comunicaciones, suministro de energía y de combustible, toda la gestión aeroportuaria, etc.) e incluso a la construcción de aeronaves y los talleres de mantenimiento, no ha escapado a los efectos del COVID-19, como demostraremos en las páginas siguientes.

Ese impacto adverso se hace notar en la suspensión de los vuelos, principalmente de transporte aéreo de pasajeros, debido al cierre de fronteras impuesto tempranamente por muchos Estados; en la dificultad para repatriar a los nacionales o residentes que quedaron varados en el extranjero; en la inejecución de cientos de miles de contratos de transporte aéreo cuyos tickets fueron adquiridos y pagados por los pasajeros, y la incertidumbre que genera el derecho a realizar el vuelo en el futuro 0 al menos a recuperar todo o parte de lo abonado; en el grounding o puesta en tierra de miles de aeronaves (específicamente, del $80 \%$ de la flota mundial de aviones) que dejaron de operar por causa del cierre de fronteras; en el costo semanal que ese grounding le genera a las aerolíneas y el gasto que tendrán que asumir cuando se las vuelva a poner en funcionamiento; en la consecuente paralización de actividades aeroportuarias, que afecta principalmente a los aeropuertos dados en concesión; en la revisión de las sanciones a las aerolíneas por la no utilización de los slots; en la desprogramación de los pedidos de construcción de aeronaves y el consiguiente cierre de plantas de ensamblado o al menos el cese temporal de sus actividades; en los planes estatales de rescate económico de las aerolíneas que vieron interrumpido de buenas a primeras el flujo de dinero en efectivo o electrónico; en la creciente situación de falencia o quiebra de la industria debido a la falta de liquidez.

También se observa su impacto en la interrupción de los contratos de leasing de aeronaves y su relación con el incumplimiento de los derechos de garantía sobre esas aeronaves; en el cese de los seguros y las cauciones; en la revalorización del rol a desempeñar por los sistemas de aeronaves pilotadas a distancia (RPAS, según sus siglas en inglés); en las prórrogas automáticas de las licencias al personal aeronavegante; etc. (Gómez, 2020, pp. 7-8).

Adicionalmente, la drástica reducción de vuelos internacionales obligará a la Organización de Aviación Civil Internacional - OACI a replantear el sistema CORSIA de

(1) Peter Frankopan (2016) textualmente expresa lo siguiente:

The most important effect that the Mongol conquests had on the transformation of Europe, however, did not come from trade or warfare, culture or currency. It was not just ferocious warriors, goods, precious metals, ideas and fashions that flowed through the arteries connecting the world. In fact, something else entirely that entered the bloodstream had an even more radical impact: disease. An outbreak of plague surged through Asia, Europe and Africa threatening to annihilate millions. The Mongols had not destroyed the world, but it seemed quite possible that the Black Death would (p. 178). 
compensación y reducción de emisiones de carbono por parte del transporte aéreo internacional(2).

En suma, el coronavirus ha hecho desembocar a la humanidad y a los Estados en una crisis que afecta a múltiples escenarios en múltiples escalas.

\section{La acción de ciertos organismos internacionales ante el COVID-19}

Ante todo, debemos recordar que el artículo 14 del Convenio de Chicago de 1944 sobre Aviación Civil Internacional(3), establece que cada Estado contratante se compromete a adoptar medidas efectivas para impedir la propagación de enfermedades contagiosas por medio de la navegación aérea. El citado artículo debe ser interpretado e implementado según las normas y métodos recomendados en el Anexo 9 del Convenio de Chicago, sobre "Facilitación".

A su vez, dentro del marco del artículo 5 del Convenio de Chicago, la OACl emitió la Comunicación EC 6/3 - 20/55, con fecha 15 de abril, instando a los Estados miembros a tomar varias medidas ante las restricciones crecientes del tránsito aéreo que estaban imponiendo muchos países para contener la propagación del COVID-19. La OACI consideró que los "vuelos de repatriación" debían ser incluidos dentro de esas medidas como "vuelos humanitarios"(4), con el fin de garantizar que se concedan con rapidez las autorizaciones necesarias para la entrada, salida y tránsito de las aeronaves que los lleven a cabo. El mismo organismo internacional recomendó realizarlos al amparo del artículo 5 del Convenio de Chicago, relativo a la prerrogativa de las aeronaves extranjeras que realicen vuelos comerciales no regulares, de transportar a pasajeros hacia y desde su territorio con sujeción a las condiciones impuestas por los Estados.

Enfocándonos exclusivamente en la industria aeronáutica, las respuestas a cada uno de los escenarios y escalas atravesados por esta pandemia, pueden agruparse en tres momentos: (i) mitigación de la crisis, (ii) salida de la crisis y (iii) recuperación del sector.

Respecto de las medidas tomadas para mitigar la crisis y para salir de ella, consideramos que, en general, las agencias internacionales especializadas en gestionar políticas de prevención e intervención en la salud a nivel mundial, y en la aviación civil, así como los organismos enfocados en la integración económica regional, tales como la Organización Mundial de la Salud - OMS, la Organización de Aviación Civil Internacional - OACI, la Comisión Latinoamericana de Aviación Civil - CLAAC, y la Unión Europea - UE, respectivamente, han reaccionado tardíamente, o al menos más tarde que los Estados, quienes dieron el primer paso apresurándose a cerrar a largo plazo sus fronteras políticas a todo medio de circulación transfronterizo de personas. Por ejemplo, la OACl recién en mayo del 2020 , es decir, a cuatro meses de iniciada la propagación internacional del virus, publicó el nuevo Manual para las Administraciones de Aviación Civil sobre la "Gestión de riesgos de seguridad operacional de la aviación relacionados con la COVID-19" (Doc 10144). El mismo organismo, si bien el 15 de abril emitió un Comunicado a todos los Estados en relación con las medidas a tomar para los vuelos de repatriación de los nacionales o residentes de cada país que quedaron varados en otro Estado por causa de la pandemia y el cierre intempestivo de fronteras, se demoró más de un mes para dar a conocer los procedimientos eficaces para la tramitación de esos "vuelos de repatriación" establecidos como vuelos especiales (véase Nota de estudio RV2/DGAC - NE/12, del 21 de mayo de 2020). Y recién el 26 de mayo hizo un llamado conjunto con la Organización Marítima Internacional - OMI y la Organización Internacional del Trabajo - OIT interpelando a los gobiernos del mundo para que designen como "trabajadores clave" a las personas del sector aeronáutico (y marítimo) que realizan tareas esenciales.

La CLAAC (Oficina regional de la OACI para América Latina $)^{(5)}$ se demoró tres meses

(2) Respecto a este asunto, es menester recordar que a la aviación no se le aplica el sistema de convenios internacionales sobre cambio climático, por ende, la COP26 no tiene competencia para tratar el tema, sino que esa responsabilidad recae sobre la OACI (Capaldo, 2020).

(3) Al 10 de julio de 2020, el Convenio de Chicago sobre "Aviación civil internacional" cuenta con 193 Estados parte. Sin lugar a dudas, es uno de los tratados internacionales más exitoso desde el punto de vista del número de membresías que ha cosechado. El convenio consta de 19 Anexos.

(4) La OACI definió a los vuelos humanitarios como aquellos que tienen como finalidad atender a los connacionales de los Estados durante situaciones de emergencia producto de catástrofes climáticas u otras situaciones adversas.

(5) Son 22 los Estados miembro de la CLAAC: Argentina, Aruba, Belice, Bolivia, Brasil, Chile, Colombia, Costa Rica, Cuba, Ecuador, El Salvador, Guatemala, Honduras, Jamaica, México, Nicaragua, Panamá, Paraguay, Perú, República Dominicana, Uruguay, Venezuela. 
en realizar, el viernes 24 de abril de 2020, la primera Reunión Sincrónica Virtual de Directores de Aviación Civil de la Región SAM (RV/DGAC), precedida por tres Podcasts con líderes sudamericanos, que contó con la participación de trece Estados de la Región SAM, seis organizaciones internacionales y un fabricante de aeronaves. Y aguardó hasta junio de 2020 para dar a conocer el "Marco estratégico de la Región SAM"(6) en respuesta al COVID-19", en el que, con gran sentido práctico, se individualizan cuatro fases: (i) la de reacción inmediata de todo el sistema de aviación ante el cierre de fronteras y de las operaciones aéreas (es decir, una etapa que ya llevaba instalada unos cuatro meses); (ii) la de reinicio de operaciones, que supone el cumplimiento estricto de las recomendaciones dadas a los futuros pasajeros por las autoridades de salud, con el doble fin de generar su confianza y de gestionar de manera efectiva los riesgos de transmisión; (iii) la fase de recuperación, hasta que se retomen los niveles previos a la crisis sanitaria; y (iv) la fase de resiliencia de la industria aeronáutica.

En cuanto a Europa, recién en la tercera semana de mayo, la Agencia Europea de Seguridad Aérea (EASA, por sus siglas en inglés) y el Centro Europeo para la Prevención y el Control de Enfermedades (ECDC, también por su sigla en inglés) adoptaron el Protocolo de Seguridad Sanitaria de la Aviación COVID-19 para el reinicio seguro del transporte aéreo y la actividad aeroportuaria en Europa, con el fin de impulsar su recuperación económica en ese continente.

La excepción fue la Organización Mundial de Turismo - OMT, que a mediados de marzo de 2020 creó un Comité Mundial de Coordinación para evaluar y proponer recomendaciones a medida que vaya evolucionando la situación generada por la pandemia del COVID-19. En fecha cercana a la anterior, lanzó una guía mundial para la recuperación del sector económico más afectado por el avance del coronavirus (el documento se titula: Directrices globales para reabrir el turismo).

También fue temporánea la medida dada a conocer por la OACl la última semana de abril de 2020. Esta agencia de las Naciones Unidas (NU) procedió a crear una Fuerza de Trabajo COVID-19 para la Recuperación de la Aviación, con el objetivo de "identificar y recomendar prioridades estratégicas y políticas para Estados y operadores de la industria". El grupo de tareas dio a luz una guía con recomendaciones para el despegue de la industria aérea el 8 de junio de 2020 (el documento se titula: Take-off: Guidance for Air Travel through the COVID-19 Public Health Crisis). Los diez principios que sostienen esa guía son: 1. Adoptar medidas armonizadas pero flexibles para proteger a las personas; 2. Trabajar como un solo equipo de aviación y mostrar solidaridad; 3 . Garantizar la conectividad aérea esencial; 4. Gestionar activamente los riesgos relacionados con la seguridad y la salud; 5 . Hacer que las medidas de salud pública de la aviación funcionen junto con los sistemas de seguridad de la aviación; 6. Fortalecer la confianza del público; 7. Distinguir reinicio de recuperación; 8. Apoyar estrategias de ayuda financiera para ayudar a la industria de la aviación; 9. Garantizar la sostenibilidad; 10. Hacer un catálogo de "lecciones aprendidas" para mejorar la resiliencia. En suma, se trata de un marco integral de medidas temporales basadas en el riesgo para las operaciones seguras de transporte aéreo durante la crisis del COVID-19.

\section{10 situaciones probables de crisis del sector aerocomercial}

La incidencia negativa de esta pandemia sobre la industria aerocomercial a escala global, regional y local, ha dado paso a uno de los capítulos más dilemáticos del derecho aeronáutico contemporáneo. Es la primera vez, en la historia de la aviación, que una industria dedicada fundamentalmente a traspasar fronteras miles de veces al día con sus aeronaves, quede paralizada en sus tres niveles: global, regional y doméstico.

En los acápites subsiguientes desarrollaremos cuál sería ese impacto respecto de 10 escenarios probables de crisis que ya afectaron o que pronto afectarán a la aeronavegación y todos los servicios, actividades y procesos asociados a ella.

\subsection{Retorno al sistema de subsidios estatales a la aviación}

Es probable que el COVID-19 impulse un retorno al sistema de subsidios del Estado durante el corto y el mediano plazo para el sostenimiento de la aviación, como lo fue desde los inicios de esta actividad y hasta la década del 70 , en la cual la Aviation Deregulation Act de 1978, del gobierno de Jimmy Carter, abrió paso a un proceso de desfinanciación estatal del sector aerocomercial que llegó hasta nuestros días.

Por considerarla una industria clave para el desarrollo geoestratégico y geopolítico de

(6) SAM: acrónimo del inglés South American. 
un país, con fuerte incidencia en las relaciones internacionales, así como en la soberanía, la defensa y el status nacional (Kobierecki, 2020, pp. 2-3), todos los Estados del mundo apoyaban y controlaban al transporte aéreo mediante subsidios y privilegios (De la Colina, 1948, p. 9) que descansaban sobre un sistema tarifario rígido aplicado a los billetes de pasaje aéreo, en un sistema de concesiones de rutas aéreas cuyo diseño de red era decidido por las autoridades aeronáuticas y no por las necesidades del mercado, y en precios predeterminados por cada Estado con el fin de evitar una competencia antieconómica y ruinosa entre las empresas. Por aquél entonces, una abrumadora mayoría de compañías aéreas eran propiedad del Estado, que actuaba de iure gestionis, es decir, como un empresario privado. Pero el capital social estaba fuertemente impregnado por los aportes del Estado. En aquella época, el concepto de aerolínea de bandera reflejaba cabalmente el status de la misma, en el sentido de que ostentaba la bandera de un país porque su propiedad pertenecía al mismo.

La Aviation Deregulation Act abandonó el sistema de subsidios y privilegios, así como el de las tarifas planas, para abrir a las compañías aéreas a la libre competencia del mercado y a la competencia tarifaria. Esa ley estadounidense, de alcance doméstico, tuvo inmediatas consecuencias transfronterizas, porque las aerolíneas norteamericanas representaban por entonces cerca del $50 \%$ del tráfico aéreo mundial, con llegada a las principales ciudades del planeta. Paulatinamente, pero sin pausa, desaparecieron los subsidios a la navegación aérea y a las aerolíneas en todas partes del mundo. Muchas cayeron en quiebra (como las pioneras Eastern Airlines, nacida en 1926, y Pan American, fundada en 1930). Otras, para sobrevivir, iniciaron un proceso de fusiones empresariales. Desde entonces, el concepto de aerolínea de bandera en sentido estricto pasó a ser apenas un seudónimo.

El aumento de la competencia comercial entre las aerolíneas, el abandono de las tarifas fijadas por el Estado como precio de los tickets aéreos y la apertura de las concesiones para la explotación de las rutas aéreas propuestas por las compañías aéreas (y no las predeterminadas por el gobierno), tuvieron dos efectos positivos: uno de ellos, para el bolsillo de la población, pues la aviación dejó de ser un medio de transporte para una clase social privilegiada y pasó a ser un medio masivo de movilidad de miles de millones de pasajeros que vuelan al año por tarifas muy accesibles. El otro fue de naturaleza logística pues, para aumentar su eficiencia, las compañías aéreas adoptaron el sistema Hub-and-Spoke ${ }^{(7)}$, utilizando algunos aeropuertos importantes como puntos centrales de conexión. Esta estrategia maximizó el uso de las aeronaves, aumentó la carga de pasajeros y mantuvo más aviones en vuelo durante más horas. Como efectos logísticos colaterales negativos, aumentó la congestión del tráfico aéreo y del aeropuerto, y eliminó muchos vuelos sin escalas que eran indispensables. $Y$ si una aerolínea dominaba un centro o hub, la falta de competencia a menudo conducía a tarifas más altas.

Es probable, entonces, que por causa del COVID-19 volvamos al período pre-Carter pues, sin un flujo sostenido de subsidios estatales al menos durante un corto y mediano plazo, las empresas de aviación difícilmente sobrevivirán. Esos subsidios podrán ser efectivos, o encubiertos. Veamos algunos de los casos que ya están siendo ejecutados.

Como ejemplo de subsidio encubierto tenemos la iniciativa del gobierno brasileño de emplear unos \$R 300 millones (unos US\$ 51.595.380, según la cotización del real al 11 de junio de 2020) para la compra anticipada de pasajes aéreos a ser utilizados durante el segundo semestre de este año para viajes oficiales de funcionarios públicos. Para llegar a esa cifra, el gobierno tomó en cuenta que, en 2019, el gasto gubernamental en boletos totalizó \$R 768,4 millones, considerando rutas nacionales e internacionales.

Otras estrategias para aliviar la situación financiera de las empresas, podrían ser los préstamos "blandos" a tasa de interés cero o muy baja, o bien la capitalización empresaria mediante la compra de acciones por el Estado, o una baja sustancial de la presión impositiva, o una prórroga de los vencimientos fiscales. En rigor, todas ellas son formas de subsidio encubierto.

Hacia el mes de abril, Portugal no descartaba la completa nacionalización de TAP Air (cuyo mayor accionista ya era el Estado) por considerarla una empresa estratégica. Dos meses después, anunciaba un aumento de su participación en el capital del $50 \%$ al $72,5 \%$, con una inversión de $€ 55$ millones. En la misma dirección, el gobierno británico analiza nacionalizar British Airways. Otras empresas que también vivirían una semi nacionalización serían EasyJet y Virgin Atlantic.

(7) Hub-and-Spoke denota un método para organizar el tráfico aéreo intercontinental, en el que un aeropuerto principal se utiliza como alimentador para los aeropuertos locales, que pasan a ser satélites de aquél (a veces abreviado como "hub"). 
A fines de abril de 2020, el Grupo Air France-KLM y Air France recibieron financiamiento por $€ 7000$ millones para enfrentar la crisis. En este caso no fueron subsidios estatales, sino dos préstamos a tasas muy convenientes (uno con respaldo del Estado francés y otro de sus accionistas directos). El primero, es un subsidio encubierto; el segundo, no. Tampoco lo es el préstamo de US\$100 millones dado por PLM Premier a Aeroméxico a fines del pasado mes de junio. PLM es el operador de su club de lealtad (Club Premier). Como contrapartida, la aerolínea acordó con la operadora PLM una extensión de 30 años en el contrato para ampliar y robustecer el programa de fidelización del cliente.

A fines de mayo, el Fondo de Estabilización Económica (FSM) de la República Federal de Alemania aprobó un paquete de medidas en favor de Deutsche Lufthansa AG, que comprende préstamos y un aumento de la participación accionaria del Estado alemán en la empresa de aviación, el cual es del $4 \%$ para el corriente año 2020 y aumentaría paulatinamente al $9,5 \%$, hasta llegar al $25 \%$ entre los años 2026 y 2027. Los aportes de capitalización del FSM serán de $€ 5700$ millones. En cuanto a los préstamos, se trata de una línea de crédito a tres años por $€ 3000$ millones aportada por el Kreditanstalt für Wiederaufbau (KfW) y bancos privados. Este es un caso mixto, de subsidio encubierto y de aportes privados a tasas de interés de mercado. Lo interesante de este caso son los derechos que el gobierno alemán se reserva para sí en razón del rescate financiero dado a la empresa. Por un lado, estipuló la exención de futuros pagos de dividendos y limitaciones en la remuneración de los cargos gerenciales. Por el otro, se reservó para sí el derecho a cubrir dos puestos en el Consejo de Supervisión, uno de los cuales será miembro del Comité de Auditoría (ALN News, 2020b). Estas prerrogativas que el gobierno se reserva, confirman que los aportes de capitalización son, en realidad, un subsidio encubierto, respecto del cual el Estado se interesa en tener cierto control y seguimiento de cómo la empresa aérea invertirá y administrará el dinero que proviene de los fondos públicos.

Como agudamente señaló Alexandre de Juniac, Director General y CEO de IATA:

Más de la mitad de la ayuda proporcionada por los gobiernos crea nuevas responsabilidades. Menos del $10 \%$ se sumará al capital de la aerolínea. Esto cambia completamente la imagen financiera de la industria. Pagar la deuda con los gobiernos y los prestamistas privados significará que la crisis durará mucho más que el tiempo que tarda en recuperarse la demanda de pasajeros (IATA, 2020, p. 9)

\subsection{Aumento de quiebras empresariales y de fusiones. Probable inicio de megafusiones}

Desde que comenzó el confinamiento global, el número de vuelos diarios cayó alrededor del $90 \%$ en algunas regiones y al momento de escribir estas líneas, casi todo el tráfico de pasajeros está suspendido. Según la IATA, en abril el descenso de vuelos trepó al $95 \%$ en comparación con el mismo mes de 2019. Como dato ilustrativo de la crisis del sector tenemos a España, que registró un descenso del $99,4 \%$ si se compara el mes de abril del 2020 con el de 2019 , mientras que la carga solo descendió un $59,7 \%$.

El Consejo Internacional de Aeropuertos alertó sobre la casi desaparición del tráfico en América Latina (ACl-LAC), cuyos aeropuertos y aerolíneas emplean a unas 430000 personas. Si se excluye a Brasil, México y Chile, que son los únicos países con alguna actividad de vuelos domésticos, la caída en la región latinoamericana fue del $97 \%$. Según estimaciones del $\mathrm{ACl}$, durante el primer trimestre de 2020 los aeropuertos de la región perdieron 40 millones de pasajeros y dejaron de ingresar más de US\$ 700 millones.

La consultora ICF (Inner City Fund) predijo que América Latina tardará seis años en recuperarse, mientras que las regiones de Estados Unidos, Canadá y Asia-Pacífico no tomarán más de cuatro. Europa necesitaría de cinco años y medio.

Como veremos unos párrafos más abajo, desde la irrupción del COVID-19, se ha desplomado el valor de las acciones de los fabricantes de aeronaves, de las aerolíneas, de las compañías de handling y de los consorcios aeroportuarios.

Cerca del $80 \%$ de la flota mundial, estimada en aproximadamente 28 mil aviones, ha quedado en tierra. A mediados de abril, sólo había 7600 aeronaves activas. No está de más recordar que las aerolíneas, durante los cuatro primeros meses del cierre del espacio aéreo de los Estados, han gastado US\$ 60000 en mantenimiento por cada uno de sus aviones en tierra (ALN News, 2020c). Semanalmente se añaden otros costos, como verificación de la presión de las ruedas de los aviones. $Y$ cada 15 días se suman gastos por:

- Inspección del tanque de combustible y realización de pruebas para asegurar que el combustible esté libre de bacterias/ microorganismos.

- Movimiento de la aeronave en tierra para cambiar el punto de apoyo de las ruedas. 
La IATA ha calculado que la industria aeronáutica tendrá un cash burn de US $\$ 60$ billones de dólares para el segundo trimestre del año (IATA, 2020, p.16), mientas que se espera que las aerolíneas pierdan US $\$ 84.3$ billones durante todo el 2020 (IATA, 2020, p. 8).

Para tener una idea aproximada de lo que ello implica, si se consulta la página Web del FMI, se constata que el $80 \%$ de los países del planeta tiene un PBI menor a los US\$ 10.

Las mayores pérdidas se registrarían en la región AsiaPacífico (US\$ 29 billones), seguida por Norteamérica (US\$ 23.1 billones), Europa (US\$21.5 billones), cercano y medio oriente (US\$ 4.8 billones), Latinoamérica (US\$ 4 billones) y África (US\$ 2 billones).

En el mismo análisis, la IATA reveló que la deuda global de las aerolíneas podría aumentar en casi US\$ 120 billones para alcanzar los US\$550 billones para fin de año, o el $92 \%$ de los ingresos pronosticados de la industria para 2021 (IATA, 2020 , p. 15). Unos US $\$ 67$ billones de la nueva deuda se componen de préstamos gubernamentales (US $\$ 50$ billones), impuestos diferidos (US $\$ 5$ billones) y garantías de préstamos (US\$ 12 billones). A su vez, unos US\$ 52 billones provienen de fuentes privadas que incluyen préstamos comerciales (US\$ 23 billones), deuda del mercado de capitales (US\$ 18 billones), deuda de nuevos arrendamientos operativos de aeronaves (US\$ 5 billones) y acceso a líneas de crédito existentes (US\$ 6 billones) (IATA, 2020, p. 9).

En promedio, cada día de este año se agregarán US\$ 230 millones a las pérdidas de las compañías de aviación. El cálculo se hace sobre la base de una estimación del número total de pasajeros que serían transportados en el 2020 (unos 2.200 millones, esto es menos de la mitad de todos los trasladados en 2019). En tal caso, las aerolíneas perderán US\$ 37.54 por pasajero. El único alivio vendrá por el lado del costo del combustible, siempre que el precio del barril de crudo permanezca tan bajo como hasta ahora.

En total, los gobiernos se han comprometido a aportar US\$ 123 billones en ayuda financiera a las aerolíneas. De esta suma, será necesario reembolsar US\$ 67 billones. El saldo se compone principalmente de subsidios salariales otorgados por el Estado bajo la modalidad "Expediente de Regulación de Empleo Temporal - ERTE" (US\$ 34.8 billones), financiamiento de capital (US\$ 11.5 billones) y desgravaciones/subsidios fiscales (us 9.7 billones).

A continuación, veremos algunos casos concretos de desplome de la economía de las aerolíneas en el mundo. TAME de Ecuador (Transportes Aéreos Militares Ecuatorianos) anunció en mayo que entraría en liquidación. En abril, Norwegian canceló el pedido de 97 aeronaves encargadas a Boeing y se presentó a concurso en sus cuatro filiales de Suecia y Dinamarca, países en donde, a diferencia de Noruega, no existe un sistema eficiente de suspensión de contratos (o ERTE) en virtud del cual el gobierno corre con todos los costes salariales durante todo el período de suspensión. El holding Avianca inició una reestructuración, tras acogerse al Capítulo 11 de la ley de bancarrota de Estados Unidos, mientras que Avianca Perú decidió abandonar el país luego de 21 años de presencia ininterrumpida.

International Airlines Group (IAG), que agrupa a las compañías aéreas British Airways, Iberia, Vueling, Aer Lingus y Level, inició un proceso de reestructuración. En la Argentina, Aerolíneas y Austral iniciaron un proceso de fusión.

En simultáneo, Iberia anunció que aún planea adquirir Air Europa, su principal competidora, y que el acuerdo con la aerolínea de Globalia incluye una cláusula "de ajuste de precio".

Hoy hay más solicitudes de reembolso que ventas de billetes de pasaje aéreo y eso está poniendo en una situación sumamente complicada a las líneas aéreas, que se están quedando sin dinero.

A este panorama debiéramos sumarle el aumento de la tasa de desempleo. La industria de la aviación genera 65.5 millones de empleos en todo el mundo, de los cuales, según estimaciones de la IATA, se perderán 25 millones en el 2020. Estos cálculos se han hecho sobre la base de una disminución del $38 \%$ de los ingresos por cada kilómetro de pasajero transportado (revenue passenger kilometers, o RPK, en la jerga aerocomercial). De aquel total de empleos perdidos, unos 2.9 millones serán latinos. Según sus cálculos, el principal afectado será la región Asia-Pacífico con 11.2 millones de puestos de trabajo perdidos, seguido por Europa con 5.6 millones menos. América Latina ocupa el tercer lugar. En cuarto y quinto lugar están América del Norte y África, cada uno de ellos con 2 millones de empleos menos, y finalmente sigue Medio Oriente con 0.9 millones de puestos de trabajo perdidos (Pierce, 2020, p. 10). Creemos que estas tasas de desempleo dibujarán un nuevo mapa en las relaciones de poder internacionales.

A decir de Thomas Piketty (2020), economista francés, la historia demuestra 
que cuando la deuda excede un cierto nivel no puedes construir un futuro sustentable.

Brand Finance calculó que, como resultado de la crisis del COVID-19, las 50 líneas aéreas más valiosas a nivel internacional podrían perder hasta el $20 \%$ de su valor de marca, lo que representa unos 20.000 millones de euros (equivalentes a US\$21.780 billones, según la cotización euro/dólar al día de publicación de la noticia, el 8 de abril de 2020). Sólo 20 de las 50 principales aerolíneas ${ }^{(8)}$ tienen suficiente liquidez para sobrevivir otros 60 días y entre ellas están listadas 6 de las 10 marcas más valiosas del mundo, mientras que hay otras 30 líneas aéreas que podrían sobrevivir más de 60 días merced a diversos factores, tales como contar con un sólido respaldo de dinero en efectivo, ser propiedad del Estado, o tener acceso a los mercados públicos o privados para afianzar su balance. Entre estas empresas se encuentran Emirates, Southwest Airlines, Air Canada y British Airways. (Brand Finance, 2020, p. 2).

En su análisis, esta consultora independiente de valoración de marca, se formuló una pregunta inquietante ¿Es este un panorama de supervivencia o el principio del fin de las aerolíneas? Si se toma en cuenta que los rankings que prepara Brand Finance cumplen con las normas ISO 10668 e ISO 20671 de valoración y evaluación de marcas, respectivamente, su conclusión fue que el escrutinio de la fortaleza financiera, la fortaleza de la marca y el valor de la marca revelaban que 20 de las 50 principales marcas del sector aerocomercial son vulnerables en estos momentos.

Thomas Piketty, al referirse al contexto social generado por el coronavirus, afirma que esta pandemia no ha hecho más que dejar expuesta la "violencia de la desigualdad". Es una metáfora interesante que mutatis mutandi también podría aplicarse al contexto aerocomercial. Decíamos que sin un flujo sostenido de subsidios estatales las empresas de aviación no sobrevivirán. Desde nuestro punto de vista, habrá una secuela de pedidos de quiebra, lo que conducirá al fortalecimiento de unas pocas aerolíneas del mundo que podrán adquirir el fondo de comercio de sus competidoras más débiles a precios de subasta pública (o con cláusula de "ajuste de precio").

Este proceso irá acompañado por otro, que creemos también será irreversible, de alianzas regionales fuertes y de megafusiones, de suerte tal que el transporte aéreo internacional podría quedar en manos de 8 ó 10 ultramegacarriers.

Un incipiente ejemplo de esta predicción es la intención declarada de Qatar Airways de tomar participación o acciones en LATAM, en Cathay Pacific, en el grupo IAG, en China Southern y en RwandAir (ALNews, 2020, pp. 1-2).

Si esta predicción se hace realidad, irá acompañada por una suerte de pugna intercontinental y dibujará un nuevo mapa en las relaciones de poder internacionales, ya que el poder de lobby y negociación que tendrán esos ultramegacarriers al momento de acordar los derechos bilaterales de tráfico aéreo será formidable, frente al que pueda tener ese $80 \%$ de países cuyo PIB no supera los US\$ 10 billones anuales. Quizá, también, suponga exhumar un viejo tratado de 1944 que jamás entró en vigor: el convenio multilateral de concesión recíproca de libertades comerciales entre todos los países $^{(9)}$.

\subsection{Caída del factor de ocupación de cada aeronave que asegura la rentabilidad de las aerolíneas. Su incidencia en el precio de los tickets aéreos}

En términos prospectivos, pueden darse a futuro varios escenarios: posibles, probables, lógicos, deseables, temidos, catastróficos. De ellos, nos interesan dos, el futuro probable o futurable y el futuro posible o futurible,

(8) Según Brand Finance, el ranking de las 10 principales líneas aéreas del mundo está encabezado por Delta, seguido por American Airlines, United, Emirates, Southwest, Air China, China Southern Airlines, Air Canada, British Airways y China Eastern. En los cinco puestos siguientes le siguen Lufthansa, Japan Airlines, ANA, Qatar Airways y Quantas.

(9) A través del Tratado de 1944, sobre "Transporte aéreo internacional", los Estados se concedían recíprocamente las dos libertades de tránsito (vuelo inocente y escala técnica) y las tres primeras libertades comerciales (de desembarcar pasajeros, piezas postales y carga en otro Estado; de embarcar pasajeros, piezas postales y carga en otro Estado; y de hacer escala intermedia en un Estado distinto del de partida y del de destino, embarcando y/o desembarcando en ella pasajeros, piezas postales y carga). Suponía, tal como se entiende en política aérea, la aceptación de una política de cielos abiertos, conforme a la cual las aerolíneas tienen plena libertad para volar a cuantos Estados y destinos deseen. Esta iniciativa no prosperó. Desde entonces, las libertades del aire se negocian de Estado a Estado, a través de convenios bilaterales de tráfico aéreo.

Si la predicción hecha en el párrafo anotado se torna real, los Estados en los que los ultramegacarriers tengan su domicilio legal, o la sede principal de sus negocios, podrían impulsar una política de cielos abiertos. Bajo esa perspectiva, el Tratado de 1944 que nunca entró en vigor, podría ser exhumado. 
porque ellos representan el punto intermedio entre el futuro catastrófico -en el presente qué puedo imaginar que provoque que todo salga mal, es decir, es un escenario de lo indeseable que se ubica en el extremo de lo temible- y el futuro utópico -qué puedo imaginar que provoque que todo salga bien, es decir, es un escenario extremo de lo deseable (Miklos \& Arroyo, 2008, p. 8,11,22).

La metodología prospectiva supone la aplicación de tres etapas: conocer, diseñar y construir. La primera implica la recolección de información diversa y dispersa proveniente de distintas fuentes con el fin de identificar los futuros posibles. La segunda, se propone elaborar modelos de la realidad sobre la base de los cuales habrán de tomarse decisiones orientadas a escenarios futuribles. La última evalúa el grado de pertinencia del futuro posible y, en función de ello, se transita un proceso que involucre a los actores sociales para respetar ciertos compromisos establecidos. Tal como lo explican Miklos y Arroyo: "En esta etapa se buscan acuerdos que se refleja en alianzas, complementariedades y prioridades compartidas. Involucra un modelo de negociación que administre el conflicto" (2008, p. 13).

Ese primer derrumbe de la demanda generado por la inevitable caída en la venta de pasajes aéreos entre marzo y junio de 2020, condujo a una merma de ingresos por avión en vuelo de tal magnitud que ya dejaron de ser rentables.

La rentabilidad anual de las aerolíneas oscila entre el $3 \%$ y el $5 \%$. Considérese que el margen de ganancia promedio por pasajero es apenas de unos $€ 7,34$ y, según la IATA (2020), el margen de beneficio neto de las compañías de transporte aéreo en 2019 fue tan solo de 3,1\%. Para que un vuelo sea rentable, la aeronave debe tener un factor de ocupación que oscila entre el $77 \%$ y el $79 \%$ (IATA Press Release, 2020). Es decir, 79 asientos vendidos por cada 100(10). Algunos países, como Argentina, por ejemplo, requieren un factor de ocupación de entre el 83 y el $85 \%$.

Dado que es improbable alcanzar esa cota en lo que resta del 2020 e incluso en 2021, los vuelos irán a pérdida. Para evitarlo, el precio de los billetes de pasaje debiera tener un aumento, que las aerolíneas calculan que oscilaría entre un $43 \%$ y un $50 \%$ más caro que el actual. A decir de Muñoz Fernández (2017, p. 12), este sería el "precio objetivo o suficiente", que consiste en añadir al "precio técnico" (que surge de la suma de los costes directos más los estructurales o fijos en función de un volumen supuesto de actividad) un margen de beneficio mínimo que la empresa desea obtener en función del volumen de actividad supuesto para el 2020 y para el 2021. Aquel incremento del 43 al $50 \%$ en el precio (IATA Press
Release, 2020), tendrá como consecuencia un derrumbe de la demanda, que se añadiría al que actualmente está padeciendo el sector. Desde esta perspectiva, quizá por un par de años la situación post pandemia se asemeje a la de los inicios de la aviación, cuando sólo volaban los miembros de las clases sociales privilegiadas.

Ambos escenarios (derrumbe de la demanda y regreso al pasado lejano que parecía superado), son futuros posibles para la aviación en el próximo bienio si el aumento del precio de billetes de pasaje aéreo se presenta como condición determinada.

A su vez, si a esos dos escenarios se le suma la prolongación del bloqueo de fronteras y las cuarentenas obligatorias en el país de destino para los pasajeros que viajen al exterior, estaremos frente a un futuro catastrófico para la aviación.

Creemos, sin embargo, que a breve y mediano plazo (lo que resta de 2020 y todo el 2021) las aerolíneas y los Estados desplegarán un conjunto de estrategias simultáneas para recuperar, en un porcentaje aceptable, la demanda perdida por causa del COVID 19. Como sostén de esta conjetura, partimos de la base de que es poco razonable que una aerolínea aplique un incremento de precios tan alto con el fin de obtener un beneficio aceptable (el promedio anual al que ya nos referimos) si ninguna persona estuviera dispuesta a pagarlo (Muñoz Fernández, 2016, p. 9) salvo, claro está, aquella minoría social privilegiada.

Tomamos en cuenta también la incertidumbre de que, al momento de escribir estas líneas, no se conoce la función aproximada de la demanda de pasajes aéreos para lo que resta del año ni para el 2021, por lo que en esta instancia es difícil determinar qué precio atraerá al máximo número de interesados en volar.

Para despejar estos escenarios de incertidumbre, Rao y Kartono (2009, pp. 13-15) proponen una lista de 19 estrategias

(10) En la publicación IATA Magazine (2020) se añade otro dato relevante: Los viajes de corta distancia generalmente necesitan un factor de ocupación de alrededor del $80 \%$ para cubrir los gastos. Si eso es literalmente imposible de lograr, las consecuencias son enormes (p. 18). 
determinantes de fijación de precios, inspirada en investigaciones previas realizadas entre 1995 y 1999 por otros autores, que se basaron en extensas evidencias empíricas obtenidas a lo largo de varios años. Tomamos en cuenta la lista de Rao y Kartono porque en ella se incluye tempranamente (2009) a los precios de Internet (Internet pricing) como uno de los métodos de fijación de precios.

Creemos que, para esta etapa pandémica de fortísima caída del factor de ocupación de cada aeronave, las estrategias determinantes que serán empleadas en mayor medida por las compañías aéreas para fijar los precios de los billetes de pasaje serán las siguientes, las cuales tal vez se empleen en el orden sucesivo que damos en este párrafo:

- precios de penetración (se establece un precio inicial bajo para acelerar la inserción del producto en el mercado aéreo);

- curva de experiencia (se establece un precio inicial bajo con el fin de generar un aumento en el volumen de ventas $y$, en esa medida, ir reduciendo costos sobre la base de la experiencia adquirida);

- precio de equilibrio (se establece el precio del producto en un punto que permita recuperar los costos de prestación del servicio).

Para los pasajeros de alto poder adquisitivo, los "precios premium" siguen siendo una opción válida para las líneas áreas árabes, por ejemplo (consiste en ofrecer una versión del producto a un precio mayor que el resto, pero con mejores prestaciones).

Para las low cost, quizá la estrategia inicial pase por el método denominado "proveedor de precios bajos" que consiste en esforzarse por ofertar el más bajo del mercado. Probablemente lo combinen con el "precio del producto complementario", por el cual el ticket aéreo se ofrece a un precio bajo, pero acompañado por artículos complementarios, como accesorios, suministros y servicios, que tendrían un precio más alto.

En cualquier momento, cualquier aerolínea podrá recurrir a cualquiera de estos otros tres métodos: "descuentos periódicos o aleatorios", esto es, rebajas periódicas o al azar del precio del producto; "precios de internet", es decir, ofrecer el mismo producto a un precio más bajo en internet que en otros puntos de venta físicos y, finalmente, el sistema de "precios dinámicos" por medio de los cuales la empresa asume una estrategia proactiva tratando de controlar las condiciones del mercado, en lugar de tener una conducta reactiva respondiendo a los cambios que puedan ocurrir en el mismo. Este último método es al que, históricamente, más recurren las aerolíneas, pues no solo segmentan el precio en función del consumidor, sino que añaden otras variables como la anticipación en la compra y/o el día de adquisición del ticket, si son o no son reembolsables, si pueden cambiarse o no, el tiempo que se pasa en destino, si el vuelo es directo o con escalas (Muñoz Fernández, 2016, p. 14, 20)

Sabido es también que los precios de los vuelos, si bien son dinámicos, están determinados por algoritmos que, aprovechando la potencia del machine learning y el Big Data, comprenden y anticipan la demanda de los usuarios mediante un proceso conocido como "gestión de rendimiento". Gracias al Big Data, las aerolíneas tienen almacenadas décadas de datos sensibles sobre los hábitos de los pasajeros y sus costumbres de pago, lo que les permite predecir los vaivenes de demanda y así ajustar rápidamente los precios de los tickets $^{(11)}$.

Creemos que la demanda futura de billetes de pasaje aéreo se generará en el mercado turístico, pero disminuirá notablemente respecto del sector corporativo (o viajes de negocios, que suelen ser breves, pero con buena disposición a pagar precios más altos), ya que este rubro habrá quedado fuerte $e$ irreversiblemente, creemos, acostumbrado por las video conferencias, los webinar, clases de capacitación virtual, entrevistas remotas, demostraciones de productos y reuniones en línea, ninguna de las cuales exige un desplazamiento espacial.

En suma, ante el hecho objetivo de caída estrepitosa del factor de ocupación de las aeronaves y el derrumbe de la demanda, y ante la certeza empírica de que pocos viajeros estarán dispuestos a pagar precios un $50 \%$ más caros que los de comienzos de año, en

(11) Esto da a lugar a que algunos consumidores sospechen prácticas desleales o tengan reservas a la hora de adquirir un ticket. Concretamente, hace ocho años Orbitz Worldwide Inc comprobó que había un reconocido buscador de hoteles por Internet que ofrecía habitaciones más caras a los usuarios de Mac que a los de Windows, porque los primeros solían estar dispuestos a pagar hasta un $30 \%$ más por noche. Una vez detectado el IP de la PC (y su marca), el buscador cambiaba el orden de los resultados para que aparecieran primero habitaciones más lujosas. 
el segundo semestre del 2020 las aerolíneas se verán forzadas a vender los billetes de pasaje a precios de penetración, combinando esta estrategia con descuentos periódicos o aleatorios y con las ventajas de precios de Internet y de los precios dinámicos. Esta táctica de penetración significa que los vuelos irán a déficit. Muy pocas empresas aerocomerciales del mundo están en condición de perder dinero por cada aeronave en vuelo. Sólo el auxilio de los Estados, bajo la forma de subsidios francos o encubiertos, y la ayuda del sector privado, les permitiría transitar esta emergencia sin sumergir a la empresa en la iliquidez.

\subsection{Incógnita sobre los programas de millaje y de fidelización del cliente}

Un efecto colateral de la caída en la venta de pasajes aéreos podría ser el fin de los programas de millaje. Como dato objetivo de la relevancia de este tema, considérese que solo One World, SkyTeam y Star Alliance representan colectivamente más del $50 \%$ del tráfico aéreo mundial. Cada una consta de 13, 19 y 26 aerolíneas asociadas, respectivamente, que en conjunto llegan a más de 1300 destinos.

Hace dieciocho años (en mayo de 2002), el semanario británico The Economist anunciaba que las millas para canje eran, de alguna manera, la segunda moneda mundial después del dólar americano (2002, p. 1). Por entonces, esa revista había calculado que el stock mundial de millas acumuladas ascendía a unos 8.500 millones, lo que representaba unos 170.000 millones de dólares. Esto era, por entonces, más que el total de los billetes de euros en circulación.

Con el único afán de ilustrar al lector sobre este acto jurídico complejo, se dice que el millaje es un derecho en expectativa con el que cuenta el pasajero que adhirió a un Reglamento Promocional, también denominado contrato de millaje o de incentivo al pasajero frecuente, para utilizar las millas que ha ido acumulando en distintos viajes y que son intercambiables entre todas las aerolíneas que integran la respectiva alianza estratégica (Gómez, 2014, p. 2; 2020, p.3). Natiello (2011, p. 7) lo define en estos términos:

Convenio por el cual una empresa de transporte aéreo, se compromete con un pasajero frecuente a acreditarle en una cuenta especialmente configurada, una cierta cantidad de puntos, avíos o millas, por cada contrato de transporte aéreo suscripto y volado por éste, y a admitir dichas millas como medio de pago de un futuro contrato de transporte aéreo para volar en rutas de la misma empresa o de otras líneas aéreas asociadas a la primera, una vez alcanzada la cantidad previamente establecida.
La jurisprudencia argentina lo consideró un "contrato innominado de generación y empleo de millas" (D’Annunzio, Juan C. contra United Air Lines Inc. sobre Ordinario, 16 de mayo de 2011, Cámara Nacional de Apelaciones en lo Comercial - Sala E).

Este es un tema que, por cierto, concierne al transporte aéreo y por ende al derecho aeronáutico, y no al derecho civil, como agudamente sostuvo la Corte Suprema de EE.UU en el caso Northwest, Inc. v. Ginsberg, 572 U.S. 273 (2014), al confirmar que la membresía en el programa estaba indisolublemente unida a los beneficios de ese programa, incluyendo la recepción de créditos de millas que pueden ser canjeados por billetes, y las actualizaciones, lo que afecta la cantidad que el demandante paga por el transporte aéreo y los servicios que se prestan durante el transporte aéreo.

De más está decir que este tópico se entronca con el anterior, pues es probable que para la reactivación de la demanda las compañías aéreas mantengan sus programas de millaje tal como estaba diseñado antes del COVID-19, al menos durante los seis a nueve primeros meses luego de la reanudación de los vuelos, tanto domésticos como internacionales. Incluso es probable que durante ese primer tramo temporal añadan algunos beneficios para atraer demanda.

Pero creemos que, pasado ese período, los programas de millaje serán sometidos a cirugía menor, mediana, o mayor, según sea el balance financiero de la empresa. Estimamos que sólo 30 de las 50 aerolíneas más valiosas podrán mantenerlo sin revisión de sus cláusulas. Las otras 20 , creemos, lo mantendrán, pero con modificaciones que implicarán para los pasajeros la pérdida de algunos de sus derechos en expectativa (recordar las predicciones de Brand Finance respecto de estas empresas líderes) ${ }^{(12)}$. El resto, es altamente probable que los reduzcan a una mínima expresión e incluso que los eliminen.

(12) Como dato útil de comparación, recordamos que IATA representa a 290 empresas aéreas, procedentes de 120 países, que controlan el 82 por ciento del tráfico mundial. A su vez, Airline Ratings califica la seguridad operacional de más de 435 aerolíneas en todo el mundo. 
Ejemplo de los programas sometidos a cambios de mediano calibre es el anunciado en febrero pasado por LATAM, conforme al cual a partir de julio comenzará a cobrar un cargo extra por los tickets de premio emitidos con las millas LATAM Pass, cuando esos canjes no sean realizados con una antelación específica ${ }^{(13)}$.

La cara opuesta de lo descripto en este acápite es la iniciativa de tres aerolíneas que, ante la falta de liquidez actual, han acudido a los clubes de millaje para financiar sus cuentas en rojo. Ya nos referimos al caso de Aeroméxico y el préstamo que le otorgó el club de millaje Premier. El segundo caso es el de Gol Linhas Aéreas Inteligentes, que a comienzos de julio afirmó que recurrirá a su programa de lealtad para obtener un avance en efectivo de 1200 millones de reales (US $\$ 225,81$ millones). Se dijo que el acuerdo funcionará mediante las ventas anticipadas de boletos para los pasajeros de Smiles Fidelidade. El tercer caso es el de United, que intentará obtener préstamos por US $\$ 5.000$ millones a través de su programa de lealtad de viajero frecuente Mileage Plus.

Si tomamos en cuenta aquel estudio hecho por The Economist, sobre la base de los pasajeros transportados en 2001 (que, según las estadísticas que lleva el Banco Mundial, ese año fue de 1.655 millones) y, por ende, del millaje acumulado en 2001 (que fue de 8.500 millones de millas), y lo proyectamos a 2019, con casi 4.400 millones de personas trasladadas por vía aérea, se deduce que el stock de millas acumuladas por los pasajeros para canjearlas por billetes en los años venideros (es decir, sin pagar el precio de ticket), supera con creces a aquellos 8.500 millones. Sobre la base de esta sencilla inferencia, desde nuestra perspectiva, la combinación entre tomar deuda a través de los clubes de lealtad más el stock de millas acumuladas por los pasajeros de esas tres aerolíneas para viajar sin pagar el costo del billete aéreo, podría ser un peligroso detonante para las finanzas de esas empresas.

\subsection{Aumento de la capacidad de bodega ofrecida para carga aérea}

Durante esta pandemia quedó demostrado que la carga aérea estuvo en primera línea en la lucha contra el COVID 19 , transportando equipos y medicamentos vitales para los centros de salud ubicados en los más diversos y remotos países. Los gobiernos entendieron las ventajas estratégicas del transporte aéreo y, en general, cooperaron para facilitar esos vuelos especiales, reduciendo costos, modificando las regulaciones de la tripulación de carga y concediendo los permisos de vuelo pertinentes. Creemos que esta experiencia debe ser considerada como una oportunidad que las aerolíneas tienen para abrirse a nuevos mercados.

Se espera que en 2020 los factores de carga promedien el $62,7 \%$, esto es, unos 20 puntos porcentuales por debajo del máximo histórico del $82,5 \%$ alcanzado en 2019 (IATA News, 2020, p. 2). En parte, ello se debería a que entre el $40 \%$ y el $45 \%$ de la capacidad de carga quedó eliminada porque alrededor del $90 \%$ de los aviones de pasajeros están forzosamente en tierra. Aun así, los resultados no son desalentadores porque, si los cotejamos con los guarismos de 2019, se espera que las toneladas totales de carga transportadas en 2020 disminuyan sólo en 10.3 millones (IATA Magazine, 2020, p. 8). A su vez, los expertos dicen que, si bien es esperable que los volúmenes caigan, no creen que el impacto sea tan grande como en la crisis financiera de 2008-09.

La solución vendría de la mano de utilizar aviones de pasajeros para vuelos exclusivamente de carga. Es decir, sacar de la parálisis a esas aeronaves y aprovecharlas como cargueros.

Este cambio de destino no está exento de problemas, pero ninguno de ellos es insoluble. Por ejemplo, si bien los aviones de pasajeros no están certificados para transportar carga en la cabina de viaje ni en los asientos, nada obsta a que las autoridades de aviación civil lo aprueben bajo la adopción de ciertos requisitos de seguridad operacional. Por el contrario, si las aerolíneas deciden quitar los asientos por completo, la aprobación gubernamental hará foco en la seguridad del vuelo, dado que se pueden llevar a bordo entre 1000 y 1500 cajas adicionales. En este caso, la decisión de la autoridad aeronáutica debe estar precedida por la intervención del constructor de la aeronave aprobando su reconfiguración, ya que ello puede cambiar el centro de gravedad del avión. A su vez,

(13) En la página Web de LATAM se advierte lo siguiente: A partir del 1 de julio de 2020, para emisiones con menos de 90 días de anticipación al viaje para vuelos nacionales y 120 días para vuelos internacionales, se cobrará un Cargo por emisión de canje* por segmento y pasajero.

Más abajo, en un desplegable, se informa, entre otros precios, que el cargo para vuelos internacionales ida y vuelta será de US\$42 (cuando el pasaje sea emitido con menos de 120 días de anticipación a la fecha del vuelo). Disponible en (acceso: 01 julio 2020): https://www.latam.com/es_py/latam-pass/como-canjear-puntos/canje-vuelos-latam/ 
como esos bultos debieran ingresar por la puerta de pasajeros, su embarque y desembarque requerirá una logística hecha a medida. Valga el ejemplo dado por Air Canada, que en seis días desarrolló, produjo, implementó, hizo certificar y aprobar la reconfiguración de la cabina de pasajeros de tres Boeing 777-300 para transportar más carga y para hacer más eficiente el traslado de mercancías e insumos médicos.

Con muy buen sentido de la urgencia, el 4 de mayo de 2020, la IATA adoptó una guía para el transporte de carga y piezas postales en aeronaves configuradas para el transporte de pasajeros, que supone un proceso previo de evaluación del riesgo (IATA, 2020a, pp. 5-15).

Por otra parte, se estima que el valor del flete aumente un $30 \%$ durante este año (IATA News, 2020, p. 2), debido a la falta de disponibilidad de espacio para carga en la bodega de los escasísimos aviones de pasajeros que están operando (pues es sabido que las mercaderías se transportan en vuelos combi -pasajeros/carga- dado el bajo número de cargueros puros). Esto haría que los ingresos por carga alcancen los \$110.8 mil millones en 2020 (frente a \$102.4 mil millones en 2019) y contribuyan en un $26 \%$ a los ingresos de la industria. Es un aumento del 12\% respecto de 2019 (IATA News, 2020, p. 3). Se presume que ese incremento se mantendrá en 2021 con un $25 \%$ más de demanda que la que se ha previsto para el 2020 (IATA Magazine, 2020, p. 15).

Por todo lo expuesto, deducimos que, para contrabalancear la caída de ingresos por el desplome en la venta de billetes de pasajes, es previsible que las empresas aumenten considerablemente su oferta de bodega para transporte de carga, que no conlleva los mismos riesgos de contagio que la movilización masiva de personas de un país a otro. Creemos que ese aumento de disponibilidad de bodega podría contribuir al descenso del valor de flete, haciéndolo más competitivo, lo que descartaría el pronóstico de la IATA comentado en las dos primeras líneas del párrafo anterior.

Esto supondrá una reconversión del sector aerocomercial, la readaptación de las aeronaves y un rediseño de las cadenas logísticas que, inexorablemente, debe ir acompañado por un desarrollo previo en los aeropuertos para paliar la insuficiente oferta de infraestructura o servicios para la carga que se observa en la mayoría de ellos a escala mundial (almacenamiento refrigerado, aduana, control sanitario, etc.).

En resumen, consideramos que el panorama carguero se vería favorecido por cuatro circunstancias: (i) una buena parte de los aviones de pasajeros que forzosamente están en tierra (grounding) podría utilizarse para el transporte de mercancías; (ii) la baja en el precio del jet fuel. En 2019 el combustible para aviones promedió los US\$ 77 por barril, mientras que el promedio para 2020 es de US\$ 36.8 por barril. Desde esta perspectiva, se estima que el combustible represente apenas el $15 \%$ de los costos totales, frente al $23,7 \%$ en 2019 (IATA
Magazine, 2020, p. 8); (iii) es el medio de transporte más eficaz y veloz para garantizar que las cadenas de suministro mundiales se mantengan para los materiales más urgentes, incluidos los alimentos; (iv) en razón de las políticas de cuarentena y de distanciamiento social implementadas por los Estados, es previsible el marcado aumento de los productos comprados en línea por clientes que residen en cualquier punto del planeta y que, en muchos casos, llegarán a sus destinatarios a través de vuelos cargueros.

En comparación con la evaporación de la demanda de compra de tickets aéreos, creemos que la carga presenta un futuro más alentador.

\subsection{Redefinición de la logística}

La función logística es una parte de la gestión de la cadena de suministro (supply chain management) que planifica, implementa y controla la gestión eficiente y efectiva del flujo directo e inverso y el almacenamiento de bienes, servicios e información relacionada entre el punto de origen y el de consumo en función de los requisitos del cliente (Servera Francés, 2010, p. 227). La logística, entonces, es un concepto estratégico y a la vez sistémico (Pinheiro de Lima et al., 2017 , p. 270) dentro de la cual está inserto el transporte. No ha de olvidarse que, si bien el medio aéreo apenas representa un 3\% del transporte mundial de cargas, el $60 \%$ del valor agregado del comercio internacional sale por avión (Müller et al., 2020, p. 30). Una logística eficiente ayudaría a agregar aún más valor.

La interrupción casi total de los vuelos de pasajeros, en cuyos aviones, como se dijo, también se transporta carga, sumada al escaso número de vuelos cargueros puros, quebraron las cadenas de pre-producción, producción y post-producción en las que el transporte aéreo jugaba un rol decisivo.

"Mantener abiertas las líneas de suministro también respalda los empleos en las economías locales; por ejemplo, productores de productos perecederos en África y América Latina", dijo Glyn Hughes, Jefe Global de Carga Aérea de IATA.

Habrá que restablecer la cadena de suministro a través de una redefinición de la 
logística del transporte de carga aérea y de las inversiones necesarias en obras de infraestructura aeroportuaria, como ya hemos señalado.

Parte de esa redefinición de la logística del transporte aéreo y su enlace con el resto de la gestión de la cadena de suministro incluye la readaptación de ciertas normas jurídicas, la pronta certificación de las aeronaves de pasajeros reconfiguradas a carga, completar la despapelización del comercio internacional con una mayor penetración del e-freight y de la e-Air Way Bill, activar las autorizaciones gubernamentales para realizar vuelos no regulares (cuya conceptualización en español no es exactamente la misma que la expresión inglesa de vuelos charter), o lo que es lo mismo, una vigorización de los contratos de fletamento total y parcial de aeronaves, sea por tiempo o por viaje. A esto debe sumársele la construcción gradual de redes de vuelo que satisfagan la demanda de la carga (como el transporte de flores y frutas frescas), que por cierto difiere de la red de vuelos regulares de pasajeros (IATA Magazine, 2020, p. 29).

Esos nuevos corredores aéreos demandarán una logística que aún está por diseñarse, tanto desde la gestión sistémica como desde el marco legal regulatorio. Respecto de este último, tienen que tener mejor calidad legislativa las normas que regulan el transporte intermodal, las relativas a la simplificación de los trámites que autorizan los vuelos no regulares, las vinculadas a la certificación de las tripulaciones de carga y a las largas cuarentenas impuestas por algunos países sobre ellas, lo que claramente no permitiría que la carga opere de manera eficiente a la vez que supondría una enorme presión para las tripulaciones.

Un escollo logístico urgente por resolver es la reapertura de los aeropuertos, tanto los principales como los de alternativa (hasta ahora cerrados por causa de la casi inexistencia de vuelos internacionales y domésticos). Esto debe ir unido a una flexibilización en el uso de los slots por parte de las aerolíneas cargueras, que operarán, como presumimos, bajo distintas formas de fletamento o vuelos no regulares.

Los aeropuertos son los que más deudas pendientes tienen con la gestión logística. Tienen que ampliar los espacios para almacenamiento de la carga, contar con instalaciones para recibir carga congelada, mejorar el enlace intermodal, eliminar los desajustes espaciales en la cadena puerta-a-puerta, ampliar las inversiones en gestión del tráfico aéreo (ATM), volcándose preferentemente hacia la navegación PBN (Performance-Based Navigation); contar con tijeras para colocar los pallets con carga en la bodega del avión, aumentar el número de puestos de control aduanero, fitosanitario y zoosanitario, así como mejorar la coordinación entre los fiscalizadores e inspectores. Todos estos aspectos forman parte de un eslabón crítico de la cadena logística vinculada al transporte aéreo, esto es, la manipulación de la carga. La IATA elaboró, en 2016, una matriz para el manejo de carga general, animales vivos, carga perecedera, medicamentos sensibles a la temperatura, mercancías peligrosas, dispositivos de carga unitaria, seguridad, intercambio electrónico de datos (mensajería EDI), correo y aduanas (IATA, 2016) que en estos tiempos adquiere crucial importancia.

Debe pensarse en contar con nuevos hubs para carga, que no necesariamente habrán de ser los mismos hubs que para el transporte de pasajeros. Una estrategia logística para consolidar esos hubs serían las alianzas de líneas aéreas destinadas al transporte de carga. Al día de hoy, sólo hay una, Sky Team Cargo, creada en el año 2000 a partir de la iniciativa de cuatro líneas que formaban parte de la alianza Sky Team para pasajeros (Aeroméxico Cargo, Air France Cargo, Delta Air Logistics y Korean Air Cargo). En el año 2013 se sumó Aerolíneas Argentinas Cargo.

En América Latina queda mucho por hacer. Esta demostrado en los informes sobre "índice de desempeño logístico" preparado por el Banco Mundial. En el último ranking global 2018-2019, que se presenta bienalmente, la lista está encabezada por Alemania, seguida por Suecia, Bélgica, Austria y Japón. Los países latinoamericanos mejor rankeados dentro los 100 primeros (de un total de 160) son: Chile (34), Panamá (38), México (51), Brasil (56), Colombia (58), Argentina (61), Ecuador (62), Costa Rica (73), Paraguay (74), Perú (83), Uruguay (85), República Dominicana (87) y Honduras (93).

Las principales debilidades logísticas latinoamericanas en materia de transporte aéreo de carga son la falta de inversiones en innovación; la poca eficacia de las normas ambientales; las aerolíneas de bandera nacional tienen economías débiles para hacer esas inversiones; es percibido por los operadores locales como: (i) no competitivo en materia de precio del flete; (ii) falta de relación con los clientes finales, tales como el cargador y el consignatario; (iii) no hay "agentes aeronáuticos" que cumplan el mismo rol que los "agentes marítimos" asumen en ese otro medio de transporte. En cuanto a los factores que amenazan un buen desempeño logístico en la región tenemos las escasas ayudas a la navegación en el espacio aéreo 
(ATM - Air Traffic Management); la aparición de nuevos competidores como Amazon; y las restricciones para vuelos nocturnos.

En suma, si bien es difícil evaluar exactamente cómo se desarrollará la demanda para este sector, no hay duda de que la demanda reprimida equilibrará esta caída, al menos inicialmente (IATA Magazine, 2020, p. 29). Queda en manos de los operadores aéreos y aeroportuarios, así como de las políticas gubernamentales, transformar un escenario adverso en una oportunidad para crecer y posicionarse.

\subsection{Desarrollo del eje aeronáutico-sanitario y} fortalecimiento de un área de cuasi vacancia disciplinar

Se vislumbra el fortalecimiento del estrecho trabajo interdisciplinario entre el sector aerocomercial y el sanitario, con la implementación de estándares de bioseguridad y la homogeneización de las regulaciones sanitarias para que sean efectivas a nivel mundial.

Un comienzo de ese abordaje transversal se dio en 2006 con la creación del CAPSCA (Collaborative Arrangement for the Prevention and Management of Public Health Events in Civil Aviation). Es un programa voluntario de colaboración intersectorial entre múltiples organizaciones, administrado por la OACl y la OMS. Intervienen la IATA, IFALPA (International Federation of Air Line Pilots' Associations), la OMT-WTO, la OCHA (United Nations Office for the Coordination of Humanitarian Affairs), la FAO (Food and Agricultural Organization), el WFP (World Food Programme), la OIM-IOM (International Organization for Migration), el IBAC (International Business Aviation Council), el ACl (Airports Council International), la MedAir (an International SOS Company), el ICCAIA (International Coordinating Council of Aerospace Industries Associations), la ITF (International Transport Worker's Federation), la GHAO (Global Humanitarian Aviation Organization), el DFWO (Dutty Free World Council), la FSF (Flight Safety Foundation), la OIE (World Organization for Animal Health), la IAEA (International Atomic Energy Agency), el CDC (Center for Diseases Control and Prevention), y el UNDP (United Nations Development Programme).

Sus objetivos más relevantes son: (i) mejorar la planificación de la preparación y la respuesta a eventos de salud pública que afectan al sector de la aviación; (ii) garantizar un transporte aéreo seguro y económicamente viable (Convenio de Chicago); (iii) asistir a los Estados con la implementación del Reglamento Sanitario Internacional (RSI) de la OMS; (iv) capacitar y evaluar a los Estados en la implementación de planes nacionales de preparación para una pandemia de aviación; y (v) facilitar la colaboración y cooperación multisectorial público-privada. Vistos los objetivos de este acuerdo cooperativo, la Resolución A40-14 de la OACI (04-10-2019) instó a los Estados a hacerse miembros de CAPSCA para mitigar la propagación de enfermedades mediante la desinsectación de aeronaves y medidas de control de vectores, entre otros medios, y subrayó la importancia del CAPSCA para ponerlos en práctica.

Por fuera del CAPSCA, pero dentro del marco de la $\mathrm{OACl}$, el grupo de expertos sobre gestión de la seguridad operacional (SMP por su sigla en inglés) redactó el documento $10144^{(14)}$, al que nos referimos al comienzo de este trabajo. Considerando la década y media de vida del CAPSCA y el contenido de la temprana Resolución A40-14, reiteramos que no es comprensible que la $\mathrm{OACl}$ haya esperado hasta mayo de 2020 para adoptar y publicar ese manual sobre la gestión de riesgos de seguridad operacional de la aviación relacionados con el COVID-19.

A la luz de los escenarios descriptos en los párrafos anteriores, resulta evidente para quien esto escribe que la $\mathrm{OACl}$ está nuevamente en mora en la elaboración de recomendaciones a sus 193 Estados miembros. Nos referimos al Manual de Medicina Aeronáutica (Doc. 8984), cuya tercera y última edición data de 2012 , sin que la OACl haya publicado una actualización que se adapte a los tiempos pandémicos que vive la humanidad. Si bien el Manual está dirigido a quienes operan las aeronaves, su aggiornamento es decisivo para que las actividades sean más seguras, que las personas sepan comunicarse, vincularse, trabajar en equipo, liderar, gerenciar estrés, fatiga y carga de trabajo, mantener adecuada conciencia situacional, gestionar errores y amenazas y tomar decisiones adecuadas al riesgo sanitario que cubre al planeta.

Traspasando las fronteras del escenario aeronáutico, la homogeneización de las regulaciones sanitarias también es clave para la recuperación del turismo mundial. La asimetría entre los resguardos exigidos

(14) Manual de la OACI para las Administraciones de Aviación Civil sobre la gestión de riesgos de seguridad operacional de la aviación relacionados con la COVID-19. 
por las autoridades sanitarias de cada Estado es uno de los problemas a resolver, porque las medidas asimétricas contra el COVID-19 revierten los efectos que generará la apertura gradual de las fronteras.

La OTM, por ejemplo, reportó al 20 de abril, que el 100\% de los destinos del mundo había introducido restricciones sanitarias a los viajes $\mathrm{y}$, con ello, al desplazamiento de los turistas, que en mayo se había reducido en un $98 \%$ en comparación con el mismo mes de 2019 (OMT, 2020, p. 7). Estos guarismos muestran que para el corriente año habría entre 850 y 1.100 millones de turistas internacionales menos. Esa retracción del flujo turístico produciría una pérdida de entre 910000 y 1,2 billones de dólares estadounidenses en ingresos de exportación del turismo y el colapso o amenaza a unos 120 millones de empleos directos.

El rubro turístico es más eficiente a la hora de tomar decisiones. Lo prueba el primer sello mundial de seguridad e higiene lanzado a fines de mayo por el Consejo Mundial de Viajes y Turismo (WTTC, por sus siglas en inglés), con el respaldo de la OMS y la OMT. Es una estampilla que certifica que esa empresa o gobierno implementó las medidas de seguridad e higiene indispensables para recibir a los turistas. El impacto positivo de este sello sobre la aviación es indiscutible; de ahí que se lo articule con el documento "Takeoff: Guidance for Air Travel through the COVID-19 Public Health Crisis" adoptado hacia esa misma fecha por la OACI.

Como epílogo, consideramos que si se supera el letargo que ostenta el trabajo interdisciplinario, su revigorización irá acompañada de un predecible fortalecimiento de la medicina aeronáutica (un área de vacancia disciplinar en las carreras de grado y de posgrado en medicina).

\subsection{Fuerte caída de la compra de aeronaves: impacto entre los constructores de aeronaves y de aviopartes}

Los analistas más escépticos evalúan que el tráfico aéreo de pasajeros demorará entre tres y cinco años para mostrar los niveles de 2019. Por efecto transitivo, la recuperación de la actividad aeroindustrial asociada al transporte sufrirá un efecto recesivo durante el mismo lapso.

Veamos algunos ejemplos ilustrativos. El consorcio europeo Airbus decidió reducir en un tercio la producción de aviones para lo que resta del año y, en julio del 2020, desde Brasil la firma Embraer comunicó que había reducido la entrega de aeronaves en un $67 \%$. Hacia fines de julio, Aernnova, una empresa española especializada en el diseño y fabricación de aeroestructuras, anunciaba la reducción de su planta de empleados en un $20 \%$ (con más de 900 despidos). La decisión se tomó luego de que el $40 \%$ de su cartera de clientes retirase los pedidos que habían presentado. Para la misma época, ITP Aero, una compañía española dedicada a la construcción de motores y componentes aeronáuticos, anunció la reducción global de su plantilla en un $15 \%$, debido a la fuerte caída de trabajo en los principales programas de aviación comercial en los que participa. Rolls Royce, el gigante británico, explicó que este año sólo entregará 250 motores de los 450 previstos inicialmente. Ante sus finanzas en caída libre, Boeing decidió ajustar aún más las tasas de fabricación de aviones comerciales y reducir los niveles de empleo.

Este panorama tendrá un triple derrame negativo. Por un lado, el escenario anterior supone un shock para la industria de la construcción de aeronaves y un impacto adverso sobre el empleo. A la previsible retracción de la demanda de construcción de aviones, se sumará la del mercado de motores de aviación y el de fabricación de aviopartes. El grounding de aeronaves, la desprogramación por parte de las aerolíneas de cientos de aviones de sus flotas y el retiro de centenas de pedidos de construcción de aeronaves repercutirá, también, en la fabricación de repuestos.

Por otro lado, ese retroceso generará una merma en la celebración de contratos de leasing, principalmente en el ramo del leasing financiero (quizá no tanto en la modalidad de leasing operativo).

El tercer derrame negativo se cernirá sobre la innovación tecnológica y el desarrollo de nuevos prototipos de aeronaves, de motores y de aviónica. Al no haber ingresos por la compra de aeronaves, y al tener las plantas de producción operando a un 50\%, o quizá menos, no habrá flujo de liquidez o activos líquidos (Cash Flow) para invertir en investigación y desarrollo.

3.9. Probable nacimiento de una línea de subsidios a los aeropuertos dados en concesión privada ¿Financiación al uso de slots? ¿Desprivatización de los aeropuertos? ¿Nuevas formas de explotación aeroportuaria PPP?

Los aeropuertos son un factor clave para el transporte aéreo, pues brindan la infraestructura necesaria para el despegue, aterrizaje, tránsito, guarda y servicio de las aeronaves. Dada la suspensión de casi todos los vuelos comerciales, el sector aeroportuario también sufre una crisis sin 
precedentes, pues está privado de recibir a su principal cliente: las aeronaves.

Basta un puñado de casos para ejemplificar la dimensión de su crisis. A mediados de abril, el gobierno canadiense pronosticó que la recuperación del sector aeroportuario en ese país demandará unos 2 a 3 años. A fines de junio, Air Canada anunció la suspensión indefinida de 30 rutas domésticas, con el consiguiente cierre de ocho estaciones en aeropuertos regionales y el retiro permanente de 79 aeronaves de su flota. Hacia fines de mayo, era un hecho que los tres aeropuertos de Nueva York (JFK, La Guardia-Nueva York, y Newark-Nueva Jersey) habían perdido el $97 \%$ del tráfico. Luego de 10 años de bonanza económica tuvieron que pedir un rescate de US\$ 3.000 millones al gobierno nacional.

Nos preguntamos si este pedido no es la antesala de una línea de subsidios estatales a los operadores privados de aeropuertos entregados por el Estado en concesión, para paliar los efectos de esta crisis económica, tal como ya se hace con las aerolíneas. Para unos pocos Estados, otra estrategia posible sería revisar los pliegos de licitación pública de los aeropuertos y los contratos de concesión a la luz de la teoría de la imprevisión, a fin de que el gobierno retome la operación de los aeropuertos privatizados. Entendemos por imprevisión la alteración extraordinaria de las circunstancias existentes al tiempo de celebración del contrato, sobrevenida por causas ajenas a las partes y al riesgo asumido por la que resulta afectada. En tal supuesto, ésta tiene derecho a plantear judicial o extrajudicialmente, la resolución total o parcial del contrato, o su adecuación (Barocelli, 2015, p. 1; Jimenez, 2009, p. 42). Otros Estados podrían optar por aplicar la regla PPP, es decir, participación público-privada, permitiendo el ingreso de capitales privados en los aeropuertos gestionados en un ciento por ciento por el Estado (nacional, provincial, o municipal). Sería un acuerdo entre el sector público y el sector privado en el que parte de los servicios o labores que son responsabilidad del sector público es suministrada por el sector privado bajo un claro acuerdo de objetivos compartidos.

El poder de mercado de los aeropuertos a nivel mundial radica en el otorgamiento de los derechos de aterrizaje (slots, o espacios horarios para despegues y aterrizajes). Se rigen por la regla 80-20, conforme a la cual los slots asignados en aeropuertos congestionados deben ser utilizados en al menos un $80 \%$; de lo contrario las compañías aéreas se exponen a perder el derecho histórico sobre los mismos en la siguiente temporada. Sea por falta de capacidad operativa o por estrategia comercial, en ocasiones el uso arbitrario de los aeropuertos sobre los slots, llega incluso a restringir los derechos de tráfico asignados por los gobiernos ${ }^{(15)}$. Analizado desde el punto de vista del derecho constitucional, esa práctica aeroportuaria conculca el derecho de propiedad pues, según consideran los especialistas en derecho administrativo, toda concesión (tales como los derechos de tráfico que los Estados conceden a las aerolíneas) se integra al derecho de propiedad del concesionario.

Varios países han adoptado medidas para flexibilizar las sanciones y multas que aplican los concesionarios a las compañías aéreas por falta de uso de los slots. Promediando el mes de marzo, la Comisión Europea expresó su voluntad de apoyar al mercado aerocomercial, permitiendo que las aerolíneas mantengan sus franjas horarias (slots) en los aeropuertos, aunque no operen vuelos debido al COVID-19. Lo mismo hizo EE.UU, en donde la Federal Aviation Administration tomó la decisión de suspender temporalmente las reglas de uso mínimo de slots en los aeropuertos de ese país. Esta política en favor de las aerolíneas, las enfrenta con los operadores aeroportuarios. O lo que es lo mismo, enfrenta a la IATA con la $\mathrm{ACl}$ (Airports Council International). De ahí que, a fines de junio, la $\mathrm{ACl}$ manifestara su preocupación a los gobiernos de que "la suspensión de las reglas de slots pueda ser usada como un mecanismo para aislar los slots de las

(15) Como afirma Aldo González, "Según demuestra la experiencia internacional, los slots son insumos críticos para operar en los aeropuertos con mayor nivel de tráfico. La escasez de estos insumos, se puede constituir en una seria barrera a la entrada para nuevas aerolíneas" $(2013$, p. 2). Los Estados, mediante tratados específicos, se conceden bilateralmente derechos de tráfico aéreo internacional. En esos convenios se designan qué aerolíneas de cada Estado ejecutarán esos derechos de tráfico, con qué frecuencia semanal y desde y hacia qué puntos (aeropuertos) operarán, entre otros ítems. Sobre esa base, cada Estado luego otorgará las concesiones respectivas para que las aerolíneas nacionales y extranjeras exploten las rutas y las frecuencias comerciales concedidas. Si el aeropuerto hace un uso arbitrario de los slots, ofreciendo los peores horarios a ciertas compañías y los mejores a otras (por ejemplo, sobre la base de lo que cada una está dispuesta a pagar por la franja horaria pico), es muy probable que las empresas que usan los peores horarios tengan una demanda menor de pasajes aéreos porque los horarios de los vuelos no resultan atractivos a los pasajeros. Si esa merma está por debajo del factor de ocupación óptimo, la aerolínea no podrá resistir mucho tiempo si opera por debajo del nivel de rentabilidad. Por lo tanto, aunque por un tratado internacional tenga los derechos de tráfico acordados, quizá se vea impelida a dejar de volar esa ruta. Este es un ejemplo entre varios otros. 
realidades del mercado durante el periodo de recuperación". Son los gobiernos quienes deberán encontrar un punto de equilibrio.

\subsection{Reformulación del programa CORSIA}

Por ser la única fuente antrópica que descarga CO2 en la alta atmósfera, desde 2016 la OACl viene adoptando medidas para que sus 193 países miembro implementen un Esquema Internacional de Compensación y Reducción del Carbono (CORSIA).

Las "Medidas Basadas en el Mercado" (MBM) son parte de una canasta de estrategias orientadas al crecimiento neutro de CO2 en la aviación internacional. El promedio de emisiones de CO2 de la aviación internacional entre 2019-2020 es la línea base de crecimiento neutro, con la que se habrán de comparar las emisiones en años futuros. Ergo, desde 2021, las emisiones de CO2 que superen el promedio de 2019-2020, serán las que deben ser compensadas cada año.

Dado que la caída estrepitosa de vuelos durante el 2020 redujo a cifras insignificantes las emisiones de $\mathrm{CO} 2$ producidas por la aviación, la OACI debería reemplazar la línea base 2019-2020 por otra posterior. De lo contrario, esa línea base quedará tan baja que todas las aerolíneas del mundo se verán obligadas a comprar bonos de carbono a partir del 2021, lo que supone una nueva carga económica para ellas (o bien, para el pasajero, a quien se le podría trasladar el costo de esos bonos).

Sin embargo, la decisión adoptada por la OACl a fines de junio fue utilizar, como base, sólo el año 2019 para el Esquema Internacional de Compensación y Reducción del Carbono. La medida cuenta con el apoyo de la IATA, a nivel internacional, y de la Unión Europea y de la CLAAC, a nivel regional.

No estamos de acuerdo, porque si los expertos pronostican una lenta recuperación del sector aerocomercial, al que llevará unos 4 a 6 años alcanzar los niveles de 2019, carece de sentido práctico tomarlo como año testigo para el cálculo de las emisiones de $\mathrm{CO} 2$, pues durante un quinquenio habrá una reducción automática de las emisiones debido a la merma del número de vuelos. Es decir, tomar el año 2019 como línea base, durante el cual, respecto de 2018, hubo un incremento del $4,2 \%$ en el tráfico de pasajeros a nivel mundial, (Actualidad Aeroespacial, 2020, p. 1), supondrá fijar un nivel tan alto de emisiones que el programa CORSIA quedaría suspendido de hecho hasta que el tráfico aerocomercial internacional supere la cota de 2019 ¿Cuándo ocurrirá eso? Pues a ciencia cierta, no se sabe.

En suma, lo que postulamos es que la $\mathrm{OACl}$ reemplace la línea base por un bienio posterior al del 2019-2020, con el fin de evitar el escenario que describimos al final del párrafo anterior. De ningún modo esta sustitución supondría abandonar los objetivos de desarrollo sostenible ni los del milenio. Sería, antes bien, un acto de equidad ambiental.

\section{Conclusiones}

La industria aerocomercial juega un rol clave en la economía global, a la que aporta 65.5 millones de puestos de trabajo, genera US\$ 2.7 billones en actividades económicas y el transporte aéreo representa alrededor del $35 \%$ del valor del comercio mundial (Amankwah-Amoah, 2020, p. 2).

Por causa de la pandemia asociada al coronavirus, 2020 será recordado como el año en el que la humanidad vivió una cotidianeidad distópica, que afecta a múltiples escenarios en múltiples escalas. La aviación no escapó a esa distopía. Por el contrario, podría decirse que ha quedado muy afectada, por cuanto su recuperación a los niveles que presentaba en 2019, demandará entre 4 y 6 años.

A lo largo de este artículo hemos presentado 10 situaciones probables de crisis que afronta la actividad aerocomercial, a escala global, regional y nacional, con consecuencias a corto, mediano y a largo plazo.

Para superar esas situaciones críticas, la regla de la "participación público-privada" (PPP) sería una fórmula viable de alivio económico en el corto y mediano plazo. Del sector público se requiere la implementación de un sistema de subsidios, sean francos o encubiertos, que apuntalen la iliquidez que afrontan las empresas del rubro. Del sector privado se requieren aportes dinerarios que alivien el esfuerzo que están realizando los Estados.

Vislumbramos, no obstante, que en el corto y mediano plazo ambas acciones no impedirán la bancarrota de un gran número de aerolíneas. La circunstancia será aprovechada por las 50 empresas más sólidas del mundo para adquirirlas a precio de subasta pública. Por esa razón creemos que se avecinan tiempos de fusiones empresarias, de fusiones regionales y de megafusiones que desembocarán en la consolidación de 8 ó 10 ultramegacarriers, cuyo poder de lobby y negociación al momento de acordar los derechos bilaterales de tráfico aéreo será formidable. Ello se deberá a que, si bien estos ultramegacarriers serán entes 
transnacionales, cada uno de ellos tendrá la sede principal de sus negocios en un país determinado, el cual, a la hora de negociar bilateralmente con otros Estados los derechos de tráfico aéreo (sobre todo las libertades comerciales), tendrán todo el poder de negociación conferido por el ultramegarrier.

La estrepitosa caída en el factor de ocupación de las aeronaves destinadas al transporte de pasajeros incidirá en la formación del precio del billete de pasaje, al menos durante el mediano plazo, así como también en los programas de fidelización de los clientes. Dada la capacidad ociosa de las flotas aéreas, el panorama se presenta propicio para un repunte notable del transporte de carga, que no conlleva los mismos riesgos de contagio que la movilización masiva de personas de un país a otro. Este cambio de trebejos en el tablero de ajedrez mundial, esta reconversión a mediano y a largo plazo del sector aerocomercial, exigirá una redefinición del esquema logístico actual, al que deberán adaptarse los operadores aeroportuarios con las inversiones necesarias para aceitar su enlace con el resto de la gestión de la cadena de suministro.

La eliminación de rutas aéreas domésticas y regionales, el grounding del $80 \%$ de la flota mundial, el cierre de fronteras por los Estados, empujó a una reducción de vuelos diarios sin precedentes en la historia de la aviación. Su secuela directa, entre varias otras, fue la paralización de la actividad aeroportuaria. Es otro sector que requerirá del auxilio económico de actores públicos y privados. En algunos casos, ese auxilio supondrá la recuperación por parte del Estado del aeropuerto dado en concesión privada. En otros, supondrá el aporte de sumas de dinero estatal bajo la forma de subsidios, o bien, mediante la compra de acciones de la empresa concesionaria del aeropuerto.

Si bien consideramos que el trabajo interdisciplinario entre algunas agencias clave de Naciones Unidas, como la $\mathrm{OACl}$ y la OMS, ha mostrado cierto letargo para afrontar la crisis, creemos que su revigorización irá acompañada de un predecible fortalecimiento de la medicina aeronáutica sistémica, que hasta ahora se ha presentado en el mundo como un área de vacancia disciplinar en las carreras de grado y de posgrado en medicina.

En cuanto al compromiso ambiental del programa CORSIA, juzgamos que la decisión de la OACl es insuficiente y, por ende, debiera revisar su última iniciativa que tomar a las emisiones de CO2 del 2019 como línea base de crecimiento neutro para el cálculo del Esquema Internacional de Compensación y Reducción del Carbono, reemplazándola por un bienio posterior al del 2019-2020. Estamos en desacuerdo porque ya en el próximo quinquenio habrá una reducción automática de las emisiones debido a la merma del número de vuelos anuales. Eso supondrá fijar un nivel tan alto de emisiones que el programa CORSIA quedaría suspendido de hecho hasta que el tráfico aerocomercial internacional supere la cota de
2019. En otras palabras, tomar al año 2019 como línea base de crecimiento neutro del $\mathrm{CO} 2$ carece de sentido práctico en el corto y mediano plazo.

En suma, postulamos que a circunstancias extraordinarias se le deben aplicar soluciones extraordinarias. Por ahora, lo urgente es gestionar esta crisis del sector aerocomercial. La etapa siguiente será la de mitigación de los múltiples impactos adversos que el COVID-19 hizo recaer sobre ella. Luego vendrá la etapa de búsqueda e implementación de estímulos de la industria para reconstruir la demanda y reparar los balances deficitarios.

\section{Referencias bibliográficas}

Actualidad Aeroespacial (2020, 12 julio). El tráfico de pasajeros crece un 4,2\% a nivel mundial en 2019. https://actualidadaeroespacial.com/eltrafico-de-pasajeros-crece-un-42-a-nivel-mundialen-2019/

ALN News (2020a). Qatar Airways reafirma su participación en LATAM y otras líneas aéreas. https://aerolatinnews.com/destacado/ qatar-airways-reafirma-su-participacionen-latam-y-otras-lineas-aereas/?utm source $=\mathrm{ALN}+\mathrm{News}+\mathrm{Newsletter \& ut}$

ALN News (2020b). Alemania, al rescate de Lufthansa con 9.000 millones de euros. Https:// Aerolatinnews.Com/Destacado/Alemania-AIRescate-De-Lufthansa-Con-9-000-Millones-DeEuros/

ALN News (2020c). Aerolíneas gastan US\$ 60,000 en mantenimiento de cada uno de sus aviones en tierra, según Sky. Https://Aerolatinnews.Com/ Destacado/Aerolineas-Gastan-Us-60000-EnMantenimiento-De-Cada-Uno-De-Sus-AvionesEn-Tierra-Segun-Sky/

Amankwah-Amoah, J. (2020). Stepping up and stepping out of COVID-19: New challenges for environmental sustainability policies in the global airline industry. Journal of Cleaner Production, 271, 1-8. https://www.sciencedirect.com/science/article/ pii/S0959652620330456?via\%3Dihub

Banco Mundial (2001). Transporte aéreo. Pasajeros transportados. https://datos.bancomundial.org/ indicator/IS.AIR.PSGR

Barocelli, S. (2015).La teoría de la imprevisión en el nuevo Código Civil y Comercial. DPI Cuántico. Derecho para innovar. https://www. pensamientocivil.com.ar/system/files/2015/07/ Doctrina1452.pdf 
Brand Finance (2020). Iberia y Vueling podrían tener el antídoto para superar la crisis del COVID-19. https://brandfinance.com/news/iberiay-vueling-podran-tener-el-antdoto-para-superar-la-crisis-del-covid-19/

Cámara Nacional de Apelaciones en lo Comercial, sala E (2011, 16 de mayo). D’Annunzio, Juan C. contra United Air Lines Inc.

Capaldo, G. (2020). Transporte aéreo y COVID-19 [Entrevista]. Entrevista realizada por el Prof. Santiago Ripoll Carulla, de la Universidad Pompeu Fabra.

Christidis, P. y Christodoulou, A. (2020). The Predictive Capacity of Air Travel Patterns during the Global Spread of the COVID-19 Pandemic: Risk, Uncertainty and Randomness. International Journal of Environmental Research and Public Health; 17(10), 3356. https:// doi.org/10.3390/ijerph17103356

Comisión Latinoamericana de Aviación Civil (CLAAC) (2020a). Marco estratégico de la región SAM en respuesta a COVID 29. https://www. icao.int/SAM/eDocumentsrestore/Marco $\% 20$ estrategico $\% 20$ SAM $\% 20$ ES\%20Completo.pdf

Comisión Latinoamericana de Aviación Civil (CLAAC) (2020b). Decisión del Consejo de la OACI sobre las características de diseño del CORSIA y la pandemia COVID-19 (Nota de estudio presentada por el Punto Focal Guatemala e IATA) (CLAC/GEPEJTA/45V-NE/03). http:// clacsec.lima.icao.int/reuniones/2020/GEPEJTA-45V/NEs/NE03.pdf

Comisión Latinoamericana de Aviación Civil (CLAAC) (2020c). Línea de tiempo en la implementación del CORSIA (Nota de estudio presentada por el Punto Focal Guatemala e IATA) (CLAC/GEPEJTA/45V-NE/04). http://clacsec.lima.icao.int/reuniones/2020/GEPEJTA-45V/NEs/NE04. pdf

De la Colina, B. (1948). Política aeronáutica comercial argentina. Imprenta de la Universidad Nacional de Córdoba.

EASA - ECDC (2020). COVID-19 Aviation Health Safety Protocol. https://www.easa.europa.eu/document-library/general-publications/ covid-19-aviation-health-safety-protocol

Frankopan, P. (2016). The Silk Roads. A New History of the World. Bloomsbury Publishing.

Gómez, H. (2020). Reflexiones iniciales sobre la industria aerocomercial ante la crisis del Covid 19 \& los derechos del pasajero. Instituto Iberoamericano de Derecho Aeronáutico, del Espacio y de la Aviación Comercial. https://derechoaeroespacial.org/cont/documentos/ publicaciones/covidaereoesp2.pdf

Gómez, H. (2014), La responsabilidad del transportador en el contrato de transporte aéreo por millas. C.E.D.A.E. https://cedaeonline.com. ar/2014/02/12/la-responsabilidad-del-transportador-en-el-contratode-transporte-aereo-por-millas/

González, A. (2013). Estudio sobre el transporte aéreo de pasajeros en Latino América. Departamento de Economía, Universidad de Chile.

IATA (2020a) Guidance for the transport of cargo and mail on aircraft configured for the carriage of passengers. https://www.iata. org/contentassets/094560b4bd9844fda520e9058a0fbe2e/guidance-safetransportation-cargo-passenger-cabin.pdf

IATA (2020b) La industria de aerolíneas mejora en 2020 tras un año difícil [Comunicado 60]. https://www.iata.org/contentassets/36695cd2115 74052b3820044111b56de/2019-12-11-01-sp.pdf

IATA (2016) Facility Capability Matrix. Transparency to improve Cargo Handling.

IATA Magazine (2020). Airlines. IATA Magazine, 2.

IATA News (2020) Industry Losses to Top $\$ 84$ Billion in 2020. https://www.iata.org/en/pressroom/ pr/2020-06-09-01/

IATA Press Realese (2020) IATA Calls for Passenger Face Covering and Crew Masks. https://www.iata org/en/pressroom/pr/2020-05-05-01/

Jimenez, W. (2009) La teoría de la imprevisión ¿Regla o principio? Misión jurídica. Revista de derecho y ciencias sociales, 2(2), 17-49.

Kobierecki M. (2020). Aviation diplomacy: a conceptual framework for analyzing the relationship between aviation and international relations. Place Branding and Public Diplomacy, 1-11. Advance online publication. https://doi.org/10.1057/s41254020-00172-5

Miklos, T \&. Arroyo, M. (2008). Prospectiva y escenarios para el cambio social. FCPS-UNAM

Müller, A. et al (2020) El transporte argentino. Actores en debate. Universidad de Buenos Aires. Secretaría de Ciencia y Técnica.

Muñoz, J. (2017). Estudio de la fijación de precios en el mercado aéreo europeo. Universidad Politécnica de Cartagena.

Natiello, O. (2011). Contrato de incentivo al pasajero frecuente. Revista Latino Americana de Derecho Aeronáutico, 15

Organización de Aviación Civil Internacional (2020a). Doc 10144 - Manual de la OACl para las Administraciones de Aviación Civil sobre gestión de riesgos de seguridad operacional de la aviación relacionados con la COVID-19. https://www.icao. int/safety/SafetyManagement/Doc10144/10144 cons_es.PDF

Organización de Aviación Civil Internacional (2020b). Guidance for Air Travel through the COVID-19 Public Health Crisis. https://www.icao. int/covid/Pages/default.aspx

Organización de Aviación Civil Internacional (2020c). Procedimiento para los vuelos de repatriación durante la pandemia por COVID-19 (Nota de estudio RV2/DGAC - NE/12). Disponible en (acceso: 30 mayo 2020): https://www.icao.int/ SAM/Documents/2020-VM4-COVID19/RV2\%20 DGAC_NE12\%20VuelosRepatriacionVENrr.pdf

Organización de Aviación Civil Internacional (2020d). La OACI, la OIT y la OMI hacen un 
llamamiento conjunto a los gobiernos del mundo para que se designen como "trabajadores clave" a las personas del sector aeronáutico y marítimo que realizan tareas esenciales. OACI. https://www. icao.int/Newsroom/Pages/ES/ICAO-ILO-andIMO-issue-joint-call-to-world-governments-onneed-for-key-worker-designations-for-essentialair-and-sea-.aspx

Organización de Aviación Civil Internacional (2012). Doc 8984, AN/895 - Manual de medicina aeronáutica civil. https://www.icao.int/publications/ Documents/8984_cons_es.pdf

Organización de Aviación Civil Internacional (1944). Doc 7300/9. Convenio sobre Aviación Civil Internacional. https://www.icao.int/publications/ Documents/7300_cons.pdf

Organización Mundial del Trabajo (OMT) (2020e). Barómetro OMT del turismo mundial, mayo 2020 - Con especial enfoque en el impacto de la COVID-19 (resumen). https://www.e-unwto.org/doi/ epdf/10.18111/9789284421831

Piketty, T. (2020). Coronavirus. Thomas Piketty: "Esta crisis económica global torna aún más relevante un plan de alivio de la deuda" [Entrevista]. https://www.lanacion.com.ar/el-mundo/thomas-piketty-esta-crisiseconomica-global-torna-aun-mas-relevante-un-plan-de-alivio-dela-deuda-nid2363524

Pinheiro de Lima, O., Breval, S., Rodríguez, C., Follmann, N. (2017). Una nueva definición de la logística interna y forma de evaluar la misma. Ingeniare. Revista chilena de ingeniería, 25(2), 264-276.

Rao, V. y Kartono, B. (2009). Pricing objectives and strategies: A crosscountry survey. En V. Rao (ed.), Handbook of pricing research in marketing (pp. 9-36). Edward Elgar Publishing. https://pdfs.semanticscholar. org/0177/a995d23d3ba6c3d331e1929446b4060acffd.pdf

Servera-Francés, D. (2010). Concepto y evolución de la función logística". INNOVAR. Revista de Ciencias Administrativas y Sociales, 20(38), 217-234.

Supreme Court (2014, 2 de abril). Northwest, Inc., et al. v. Ginsberg, 572 U.S. 273 (2014)

The Economist (2002) Airline miles. Frequent-flyer economics. https:// www.economist.com/leaders/2002/05/02/frequent-flyer-economics

World Bank (2020) LPI - The Logistics Performance Index. Global Rankings 2018. 2019. https://lpi.worldbank.org/international/ global/2018.\%202019

WTTC (2020) Global Safety Stamp to Recognize Safe Travels Protocols. https://wttc.org/COVID-19/Safe-Travels-Global-ProtocolsStamp 
